\title{
Level of willingness to report to work during a pandemic among the emergency department health care professionals
}

\author{
Anas Khan', Mohammad Al Johani' \\ ${ }^{1}$ Emergency Medicine Consultant, Department of Emergency Medicine, College of Medicine, King Saud University, Riyadh-11461, Saudi Arabia.
}

\section{A B S TR A C T}

Objectives: To quantify the knowledge and attitudes of Health care providers (HCP) towards their willingness to work during an influenza pandemic. Methods: A Questionnaire based cross sectional study among the 350 emergency departments' staff in seven different tertiary hospitals in Riyadh, Saudi Arabia was conducted in Jan 2010. A structured questionnaire with items to quantify the knowledge and attitudes of health care providers based on hypothetical scenario about the occurrence of $\mathrm{H} 1 \mathrm{~N} 1$ pandemic was developed. The questionnaire was validated before it was distributed among the study subjects. Data was analyzed using SPSS Pc + 21.0 statistical software. Results: Out of the 254 responders, $190(74.8 \%)$ stated that they will report to work during a pandemic, $29(11.4 \%)$ won't, and $35(13.7 \%)$ don't know. From those who won't report or don't know; 29 (45.31\%) won't change their minds for salary increase, and $40(62.5 \%)$ won't change their mind even if it meant they were to be dismissed. About $93(36.4 \%)$ of study subjects were of the opinion that, HCP without children should primarily look after the patients. Among the HCPs, higher number of consultants and nurses were more willing to work than other HCPs. The consultants were having positive attitudes towards working during pandemics. Conclusion: Our results suggested that most participants were having positive attitudes towards willingness to work during an influenza pandemic. Their concerns should be considered, so that during a real situation faced, plans could be translated to reality smoothly.

Key words: Willingness, Emergency, Disaster, Health care providers, Report to work
Access this article online

Website:

http://nepjol.info/index.php/AJMS

\section{INTRODUCTION}

Emergency medicine is a specialty based on the knowledge and skills required for the prevention, diagnosis and management of acute and urgent aspects of illness and injury which affects patients of all age groups. During any public health emergency such as influenza, competent staffs of emergency department are an essential component of health care system to respond. Among all health care staff, the emergency department staffs are the first line in dealing with all types of emergencies and disasters. The planning of pandemics consists of patient care, health education, epidemiological surveillance, quarantine management, fever clinics and other specific duties. ${ }^{1-3}$ An effective response to an influenza emergency depends on the number of uninfected healthcare providers (HCP) willing to work. Professional duty of HCPs in emergency departments (ED) may clash with the fear of contracting influenza or its transmission to family members. ${ }^{1,2}$ As the international centers predictions reaching 30\% infection among population during the latest influenza outbreak, with emergency public health concerns rising, estimating man-power shortage in the critical areas is a must. ${ }^{3-5}$ The literature has reported that, being female, supportive staff, timing of influenza emergency, concern for family members, and personal obligations were the associated factors for less willingness to work during an influenza public health emergency. ${ }^{6-9}$ Fear of contracting illness 
during a pandemic makes HCPs resort to absenteeism during emergency situation which leads to the shortage of personnel. Motivating HCPs to attend pandemics could be achieved by ensuring them adequate personal protection rather than offering time bound financial incentives. ${ }^{10}$

Ethical issues in this field is contradicting, with no clear regulations to deal with the debate of whether to responds to duty call or run away from danger. ${ }^{11}$ The perception is that those providing emergency health care services have to perform their duties, even in the face of personal risk. Hence an emergency duty due to influenza, as with any event involving contagion or contamination, has the potential to alter the willingness of HCPs to report to work. ${ }^{12,13}$ Some of the past experiences indicate no shortage of staff and the departments were overcrowded by off-duty staff rushing to help during major emergencies. However, it is not known what will be the actual response during fatal pandemics. To improve the care during emergency situations, appropriate strategies have been adopted by considering the views of HCP.

This study was carried out to assess the knowledge and attitudes among HCPs of emergency departments of Riyadh city, towards their willingness to report to work during pandemics.

\section{MATERIALS AND METHODS}

A cross sectional observational study was carried out during the period $1^{\text {st }}$ to $15^{\text {th }}$ January 2010 , after the $2^{\text {nd }}$ phase of the H1N1 in Riyadh which is the capital of Kingdom Saudi Arabia, with an area of around $2500 \mathrm{~km} \mathrm{sq}$. and harboring a population of around 4.9 million, with most services concentrated here. ${ }^{14}$ Riyadh contains seven tertiary hospitals, each governed by a different government sector. Our inclusion criteria were: Emergency department staffs of those hospitals (consultant, resident, nurse, social worker / administrator) and exclusion criteria were: on call service rotator residents from non-emergency specialties, and interns. Stratified random sampling method from the seven emergency departments was sought; where 350 forms were distributed (each emergency department got 50 forms). After reviewing the literature, an appropriate structured questionnaire was developed. The questionnaire consists of socio-demographic characteristics \& H1N1 related information, 4 questions related to knowledge and 10 questions related to attitudes, based on the hypothetical case scenario about an occurrence of H1N1 pandemic in Riyadh. The content, construct and face validity of questionnaire was carried out. The content validation was done by emergency, disaster medicine and epidemiology consultants. A pilot study was conducted in 2 of the designated emergency departments, and appropriate changes were made.

\section{Statistical analysis}

Data was analyzed using SPSS Pc+21.0 version statistical software, Chicago, USA. Descriptive statistics (\%) were used to quantify the categorical study and outcome variables. Pearson chi-square test was used to observe the association between the categorical study and outcome variables. A p-value of $\leq 0.05$ was considered as statistically significant.

\section{RESULTS}

Of the total 350 questionnaires distributed, 254 subjects responded with complete information with a response of $72.5 \%$. Out of $254 \mathrm{ED}-\mathrm{HCPs}$, a higher of subjects were nurses (48.4\%). There were 105(41.3\%) males and among the 4 age groups distribution $166(65.4 \%)$ were in age group of 25 to 35 years (Table 1). Among the responders, only $37(14.6 \%)$ received the H1N1 vaccination. Upon asking whether they received any educational lectures about H1N1, 172 (67.7\%) responded positively.

Knowledge towards the issues related to willingness to work during pandemic

For the question, "are you fully aware of any preparedness plans in your institution during pandemics", about $155(61 \%)$ responded as yes. Only 111(43.7\%) have read about ethical issues during pandemics. The awareness about their job contract containing a term "reporting to work during pandemics", was not known by 140(55.2\%) subjects.

\begin{tabular}{lc}
\multicolumn{2}{l}{$\begin{array}{l}\text { Table 1: Distribution of Socio-demographic } \\
\text { characteristics of study subjects }(\boldsymbol{n}=\mathbf{2 5 4})\end{array}$} \\
\hline Characteristics & No. $(\%)$ \\
\hline Job & \\
Consultants & $33(13.0)$ \\
Residents & $85(33.5)$ \\
Nurses & $123(48.4)$ \\
Admin/social workers & $13(5.1)$ \\
Gender & \\
Males & $105(41.3)$ \\
Females & $149(58.7)$ \\
Age group & \\
<25y & $25(9.8)$ \\
25-35y & $166(65.4)$ \\
36-45y & $41(16.1)$ \\
$>45 y$ & $22(8.7)$ \\
Citizenship & \\
Saudi & $97(38.2)$ \\
Non-Saudis & $156(61.4)$ \\
Social status & \\
Non-Married & $101(39.8)$ \\
Married & $153(60.2)$ \\
Children living at home & \\
Do & $111(43.7)$ \\
Don't & $143(56.9)$ \\
\hline
\end{tabular}


The distribution of responses to the subsequent question: "does your contract protect you during pandemic" only $35(13.8 \%)$ responded with a 'yes' (Table 2).

Attitudes towards their willingness to work during pandemic based on a "case scenario"

The attitudes towards the willingness to work during pandemic based on the case scenario: "If a feared fatal pandemic strikes in Riyadh, with a 2-5\% mortality rate", were assessed. The willingness to reporting to the work was reported by 190 (74.8\%) study subjects. Among the 64 who don't want to report to work, salary increase could play as a motivating factor for some 35(54.7\%) to work during fatal pandemic and remaining $29(45.3 \%)$ were not willing to report to work. Fear of being removed from the job was not an issue for $40(62.5 \%)$ of study subjects whereas $24(37.5 \%)$ were willing to change their mind and report to work.

To know the professional and ethical values among the study subjects, it was asked that "if one of the staff called \& said he'll not report to work in order to protect himself \& family, do they think it's acceptable (professionally \& ethically)", $158(62.2 \%)$ responded as no which was considered as a good indicator of professional ethics. For the adequacy of manpower in ED's in Riyadh, during the pandemic: 219 $(86.2 \%)$ subjects responded negatively, implying shortage

\begin{tabular}{lc} 
Table 2: Distribution of responses of \\
study subjects towards their H1N1 related \\
experience ( $\boldsymbol{n}=254)$ & No. (\%) \\
\hline H1N1 related issues & \\
\hline Received H1N1 Vaccine & $13(14.6)$ \\
Yes & $217(85.4)$ \\
No & \\
Educational lectures & $172(68.0)$ \\
Yes & $81(32.0)$ \\
No & \\
Awareness to preparedness & $155(61.0)$ \\
Yes & $99(39.0)$ \\
No & \\
Know H1N1 victims & $200(78.7)$ \\
Yes & $54(21.3)$ \\
No & \\
Read about ethics in pandemics & $111(43.7)$ \\
Yes & $142(56.3)$ \\
No & $150(75.0)$ \\
Victims outcomes & $36(18.0)$ \\
Mild flu & $14(7.0)$ \\
pneumonia & \\
Mortality & $61(24.0)$ \\
Your contract compels you & $53(20.9)$ \\
Yes & $140(55.1)$ \\
No & \\
I don't know & $35(13.8)$ \\
Your contact protects you & $28(11.0)$ \\
Yes & $42(16.5)$ \\
Not enough & $149(58.7)$ \\
Not at all & \\
I don't know & \\
\hline &
\end{tabular}

of manpower in the emergency departments. About 102 $(40.2 \%)$ study subjects were of the opinion that the decision to report to work should be left to individual choice rather than an administrative decision. For assessing the attitudes of HCPs towards the consequences for not reporting to work during pandemics, the study subjects responses were: $36(14.2 \%)$ said they should be dismissed, $26(10.2 \%)$ said they should be suspended, $16(6.3 \%)$ said their salary should be deducted, $139(54.7 \%)$ were of the opinion to be further investigated and $37(14.6 \%)$ were for no action (Table 3$)$.

\begin{tabular}{|c|c|}
\hline Questions related to case scenario & No. $(\%)$ \\
\hline \multicolumn{2}{|l|}{ Would you report to work? } \\
\hline Yes & $190(74.4)$ \\
\hline No & $29(11.4)$ \\
\hline I don't know & $35(13.7)$ \\
\hline \multicolumn{2}{|c|}{$\begin{array}{l}\text { If other than yes, how much salary increment will } \\
\text { change your mind? }\end{array}$} \\
\hline $100 \%$ & $11(17.2)$ \\
\hline $200 \%$ & $24(37.5)$ \\
\hline Never & $29(45.3)$ \\
\hline \multicolumn{2}{|c|}{$\begin{array}{l}\text { You still won't report to work even if they will be } \\
\text { dismissed permanently? }\end{array}$} \\
\hline Yes & $24(37.5)$ \\
\hline No & $40(62.5)$ \\
\hline \multicolumn{2}{|c|}{ Is it acceptable for others to abandon workplace? } \\
\hline Yes & $63(24.8)$ \\
\hline No & $158(62.2)$ \\
\hline I don't know & $33(13.0)$ \\
\hline \multicolumn{2}{|l|}{ Think there will be staff shortage } \\
\hline Yes & $219(86.2)$ \\
\hline No & $16(6.3)$ \\
\hline I don't know & $19(7.5)$ \\
\hline \multicolumn{2}{|c|}{$\begin{array}{l}\text { Decision to report to work should be left for } \\
\text { individual choice }\end{array}$} \\
\hline Yes & $102(40.2)$ \\
\hline No & $105(41.3)$ \\
\hline I don't know & $47(18.5)$ \\
\hline \multicolumn{2}{|c|}{$\begin{array}{l}\text { What would you think will happen if you don't } \\
\text { report to work }\end{array}$} \\
\hline Dismissed & $36(14.2)$ \\
\hline Suspended & $26(10.2)$ \\
\hline Investigated & $139(54.7)$ \\
\hline No action & $37(14.6)$ \\
\hline Salary deduction & $16(6.3)$ \\
\hline \multicolumn{2}{|c|}{$\begin{array}{l}\text { What would you think Should happen to whoever } \\
\text { don't report to work }\end{array}$} \\
\hline Dismissed & $26(10.2)$ \\
\hline Suspended & $22(8.7)$ \\
\hline Investigated & $139(54.7)$ \\
\hline No action & $37(14.6)$ \\
\hline Salary deduction & $30(11.8)$ \\
\hline \multicolumn{2}{|l|}{$\begin{array}{l}\text { Do you think HCP without children should } \\
\text { primarily look after the patients? }\end{array}$} \\
\hline Yes & $93(36.6)$ \\
\hline No & $161(63.4)$ \\
\hline \multicolumn{2}{|l|}{ What do you think your mood in work? } \\
\hline Depressed & $93(36.6)$ \\
\hline Excited & $30(11.8)$ \\
\hline Neutral & $131(51.6)$ \\
\hline
\end{tabular}


Association between type of HCP's job and level of willingness to work during pandemic

The univariate analysis shows that there is an association between position of HCPs and the knowledge about the prepared plans at their institutions during pandemics, in which higher proportion of consultants $(75.8 \%)$ and nurses (74\%) were aware of prepared plans when compared with residents $(37.6 \%)$ and administrators $(53.8 \%)\left(\chi^{2}=31.51\right.$; $\mathrm{dff}=3 ; \mathrm{p}<0.0001)$. The knowledge of ethical issues during pandemics were higher among consultants and nurses, when compared with residents and administrators $\left(\chi^{2}=11.21\right.$; $\mathrm{dff}=3 ; \mathrm{p}=0.011)$. The job contract contains a term about reporting to work during pandemic were not known in higher number of consultants, followed by residents, and administrators when compared with nurses $\left(\chi^{2}=13.40\right.$; $\mathrm{dff}=6 ; \mathrm{p}=0.037)$. Lack of awareness and dissatisfaction towards protection during pandemic in their job contract was higher among consultants, residents and nurses when compared with the administrators $\left(\chi^{2}=18.24\right.$; $\left.\mathrm{dff}=9 ; \mathrm{p}=0.033\right)$. A higher proportion of consultants $(75 \%)$ responded negatively, to the decision to report to work should be left for an individual's choice rather an administrative, which indicates that consultants were having positive attitude to work during pandemics when compared with residents, nurses and administrators $\left(\chi^{2}=19.66\right.$; $\left.\mathrm{dff}=6 ; \mathrm{p}=0.003\right)$.

\section{DISCUSSION}

Many studies have been carried out across many countries to assess the willingness of HCPs to work during public health emergency, in particular during the avian flu and SARS epidemics. ${ }^{1,2,413,15,16}$ The willingness of HCPs to work during an influenza public health emergency has been studied by multiple health care disciplines. Although issues of medical professionalism have been discussed in the aftermath of the SARS epidemic, to our knowledge, only few studies have addressed this topic in relation to the anticipated influenza pandemic. ${ }^{1,2}$ Not even a single study has reported from this region, which could assess the knowledge and attitudes of emergency departments HCPs towards their willingness to work during emergency pandemics. This study has found a moderate knowledge related to the aspects of willingness to work during the pandemics, as more than $50 \%$ of HCPs were not aware of ethical issues, prepared plans of institution, and terms of their job contract. But our study subjects were having a positive attitude to attend the work during pandemics. For the hypothetical scenario; 74.8\% said they'll report to work in Riyadh during the pandemic. Understanding the factors which influence the HCP's willingness to report to work during pandemics is essential for an appropriate planning. Studies have reported about the factors associated with a willingness to work during pandemic emergency were being a male, a consultant or nurse, working in a clinical or emergency department, prior education and training on pandemics, prior experience of working during a public health emergency, self-confidence on duty, and confidence in one's employer. ${ }^{6}$ Our data shows, that consultants and nurses were more willing to report to work, but expressed concerns about the lack of protection from employee and to have proper monetary compensation. A study conducted by Qureshi et al. found that, in 47 health care facilities in 2005 at New York City $(\mathrm{N}=6,428)$, that $61 \%$ of HCP willingness to report to work during a SARS outbreak. ${ }^{1}$ But another study by Balicer et al. found that nearly half of the ED staff $(\mathrm{N}=308)$ in Maryland were willing to report to work during an influenza pandemic. The clinical staff indicated a higher likelihood of reporting to work than technical and support staff. The authors observed that increased likelihood of reporting to work during a pandemic was associated with perceived importance of one's role in overall and specific response in an emergency. ${ }^{4}$ Irvin et al. in their study found that incentives, even for triple of the pay have no effect on their decision not to report to work during pandemics. ${ }^{5}$ In our study we have observed that 'a HCP can abandon work in order to protect him/herself and their families' was not accepted by $62.2 \%$, which indicates a positive attitude among our study subjects. The decision to report to work should be left to individual choice rather than an administrative decision was disagreed by $41.3 \%$. This is one of the debatable issues gaining momentum among the administrators and health managers. About $54.7 \%$ of our HCPs believed that for anyone who doesn't report to work during a pandemic should be investigated, rather than any permanent dismissal or salary deduction, whereas $36.4 \%$ agreed that any HCP who have no children at home should primarily look after the patients during a pandemic which is a subjective attitude. A survey conducted in Germany 2006, by Ehrenstein et al. $(\mathrm{N}=644)$ concluded that $52 \%$ of their study subjects disagreed with a view that 'HCP can abandon his work during a pandemic'. Only $21 \%$ agreed that a HCP without children should primarily care for influenza patients. ${ }^{2}$ The actual HCP behavior during a pandemic should not solely be predicted by their answers to the hypothetical questions of a survey. Nevertheless, our study illuminates aspects of HCP perceptions of risk and duty by creating a possible case scenario of influenza pandemic, which is different from the other surveys reported in the literature.

Our results suggested that most participants (consultants and nurses) recognized their professional duty and having positive attitudes towards willingness to work and treat patients during an influenza pandemic. This study is having a limitation of generalizability due to a response rate of $71 \%$. The authors recommend the need of professional and ethical guidelines explaining the requirements of society with personal risks so as to help HCP fulfill their duties in the case of a pandemic influenza. More studies in different 
healthcare settings of other gulf countries are needed to learn more about the knowledge and attitudes of health care providers of emergency departments. Efforts should aim on building an ethical consensus attributed to our own culture and variables. The administration should be ready before the moment of truth by assessing the trends in its department. It's supposed to be proactive in educating its staff periodically about all related information and provide all means for protections.

\section{REFERENCES}

1. Qureshi K, Gershon R, Sherman M, Straub T, Gebbie E, McCollum M, et al. Health care worker ability and willingness to report to duty during catastrophic disasters. J Urban Health 2005; 82: 378-388.

2. Ehrenstein BP, Hanses F and Salzberger B. Influenza pandemic and professional duty: family or patients first? A survey of hospital employees. BMC Public Health 2006; 6: 311-319.

3. Levin PJ, Gebbie EN and Qureshi K. Can the healthcare system meet the challenges of Pandemic flu? Planning, ethical and workforce consideration. Pub Health Reports 2007; 122: 573578.

4. Balicer RD, Omar SB, Barnett DJ and Everly GS. Local public health workers' perceptions towards responding to an influenza pandemic. BMC Public Health 2006; 6: 99-106.

5. Irvin C, Cindrich L Patterson W, Ledbetter A and Southall A. Hospital personnel response during a hypothetical influenza pandemic: will they come to work? Academy of Emergency Medicine Journal, May 2007, 14(5, Suppl 1):13a.

6. Seale H, Leask J, Po K and MacIntryre CR. "Will they just pack up and leave?" Attitudes and intended behavior of hospital health care workers during an influenza pandemic, BMC Health Serv Res 2009; 9:30-37.
7. Damery S, Darper H, Wilson S, Greenfield S, Ives J, Parry J, et al. Health care workers' Perceptions of the duty to work during an influenza pandemic. J. Med. Ethics 2010; 36(1):12-18.

8. Chaffee M. Willingness of health care personnel to work in a disaster: an integrative review of the literature. Disaster Med Public Health Prep 2009; 3(1):42-56.

9. Butsashvli M, Triner W, Kamkamidze G, Kajaia M and Anne McNutt L. Knowledge and anticipated behavior of health care workers in response to an outbreak of pandemic influenza in Georgia. J Infect Developing Countries 2007; 9(3):329-332.

10. Stokowski LA. Ethical Dilemma for Healthcare Professionals: Can We Avoid Influenza? Medscape Infectious Diseases 2009. Available at: http:// www.medscape.com/viewarticle/702371, accessed on May 3, 2011.

11. Irvin CB, Cindrich L, Patterson $W$ and Southall A. Survey of hospital healthcare personnel response during a potential avian flu pandemic: will they come to work? Pre hospital Disaster Medicine 2008; 23(4):328 - 335.

12. Singer PA Benatar SR, Bernstein M, Daar AS, Dickens BM, MacRae SK, et al. Ethics and SARS: lessons from Toronto. BMJ 2003; 327; 1342 -1344.

13. Tzeng HM. Nurses profession care obligation and their attitudes towards SARS infection control measures in Taiwan during and after the 2003 epidemics. Nurs Ethics 2004, 11(3): 277-289.

14. Riyadh City official website, accessed on May 24,2010. http:// www.arriyadh.com/ar/AboutArriy//?1=1\&menuld=2815

15. Koh D, Lim MK, Chia SE, Ko SM, Qian F, Nq V, et al. Risk perception and impact of severe acute respiratory syndrome (SARS) on work and personal lives of health care workers in Singapore: what can we learn? Med Care 2005; 43(7):676682.

16. Shiao JS, Koh D, Lo LH, Lim MK and Guo YL. Factors predicting nurses' considerations of leaving their job during the SARS outbreak. Nurs Ethics 2007; 14(1):5-17.

17. Shabanowitz RB and Reardon JE. Avian flu pandemic - flight of the health care worker? HEC Forum 2009; 21(4):365-385. Authors Contribution:
AK-Designed \& developed study protocol, analyzed the data and drafted the manuscript; MAJ - Contributed to the study design, coordinated in the data collection
and reviewed the manuscript.

Source of Support: Nil, Conflict of Interest: None declared. 